\title{
Cancer Patient Experience in a Nuclear Medicine Department: Comparison Between Bone Scintigraphy and ${ }^{18}$ F-FDG PET/CT
}

\author{
Ana M. Grilo ${ }^{1,2}$, Lina Vieira ${ }^{1,3}$, Elisabete Carolino ${ }^{1}$, Melissa Costa $^{4}$, Salomé Galaio ${ }^{4}$, Inês Melo ${ }^{4}$, Ana Geão ${ }^{5}$, \\ Andrea Santos ${ }^{5}$, and Paula Colarinha ${ }^{5}$ \\ ${ }^{I} H \& T R C$-Health \& Technology Research Center, ESTeSL-Escola Superior de Tecnologia da Saúde, Instituto Politécnico de \\ Lisboa, Lisbon, Portugal; ${ }^{2}$ CICPsi-Research Center for Psychological Science, Faculty of Psychology, University of Lisbon, \\ Portugal; ${ }^{3}$ CIMOSM, ISEL—Centro de Investigação em Modelação e Optimização de Sistemas multifuncionais, Escola Superior de \\ Tecnologia da Saúde, Instituto Politécnico de Lisboa, Lisbon, Portugal; ${ }^{4}$ Escola Superior de Tecnologia da Saúde, Instituto \\ Politécnico de Lisboa, Lisbon, Portugal; and ${ }^{5}$ Serviço de Medicina Nuclear, Hospital CUF Descobertas, Lisbon, Portugal
}

\begin{abstract}
Our objective was to assess the anxiety level in cancer patients undergoing nuclear medicine exams and to identify how professionals can improve patient experience. Methods: In total, 94 patients undergoing ${ }^{99 m} \mathrm{Tc}$-hydroxymethylene diphosphonate (99mTc-HDP) bone scintigraphy (BS) or ${ }^{18} \mathrm{~F}-\mathrm{FDG} \mathrm{PET} / \mathrm{CT}$ completed 2 scan-experience questionnaires and the Spielberger State Anxiety Inventory (STAI-S) before the scan and after image acquisition. Results: Before the exam, the mean anxiety levels were higher for the $99 \mathrm{mTc}-\mathrm{HDP}$ BS group than for the ${ }^{18} \mathrm{~F}-\mathrm{FDG}$ PET/CT group. After the exam, the opposite was true. Both groups experienced a reduction in anxiety after the scan (prescan score, 51.75 for $99 \mathrm{mTc}-\mathrm{HDP}$ BS and 44.67 for ${ }^{18} \mathrm{~F}-\mathrm{FDG}$ PET/CT; postscan score, 36.70 for ${ }^{99 \mathrm{~m} T c-H D P} \mathrm{BS}$ and 38.82 for ${ }^{18} \mathrm{~F}-\mathrm{FDG}$ PET/CT). The greatest anxiety factor for the $99 \mathrm{~m}$ Tc-HDP BS group was the duration of the exam (mean $\pm \mathrm{SD}$, $5.34 \pm 2.08)$, whereas for the ${ }^{18} \mathrm{~F}-\mathrm{FDG}$ PET/CT group it was the result $(5.40 \pm 1.80)$. Conclusion: Patients undergoing nuclear medicine exams in an oncologic context had significant anxiety levels before and after their scans. However, ${ }^{99 m}$ Tc-HDP BS and ${ }^{18} \mathrm{~F}-\mathrm{FDG}$ PET/CT had different triggers. It is of extreme importance that health-care professionals be aware of these peculiarities and adjust their procedures accordingly.
\end{abstract}

Key Words: anxiety; ${ }^{99 m}$ Tc-HDP bone scintigraphy; ${ }^{18} \mathrm{~F}-\mathrm{FDG}$ PET/CT; oncology; nuclear medicine; patient concerns

J Nucl Med Technol 2020; 48:254-262

DOI: 10.2967/jnmt.119.239285

$\mathbf{N}$ uclear medicine (NM) has been playing an increasingly important role in the diagnosis, staging, prognosis, therapy, treatment planning, and restaging of various malignant neoplasms (1). Low-dose ${ }^{18} \mathrm{~F}-\mathrm{FDG}$ PET/CT and bone scintigraphy (BS) are the most common NM exams

\footnotetext{
Received Nov. 13, 2019; revision accepted Apr. 16, 2020.

For correspondence or reprints contact: Ana M. Grilo, Universidade de Lisboa, Avenida Dom João II, Lote 4.69.01, Parque das Nações, 1990-096 Lisbon, Portugal.

E-mail: ana.grilo@estesl.ipl.pt

Published online Jun. 9, 2020

COPYRIGHT @ 2020 by the Society of Nuclear Medicine and Molecular Imaging.
}

used in cancer patients. ${ }^{18} \mathrm{~F}-\mathrm{FDG}$ PET/CT is an imaging modality that enables the detection of primary tumors and metastases by visualization of the increased glucose consumption of malignant tissue. BS is a highly sensitive diagnostic NM imaging technique that uses a radiotracer to evaluate the distribution of active bone formation in the skeleton related to malignant and benign disease (2). Although these exams currently constitute a quasiroutine for these patients, they are not devoid of psychologic impact. It is known that they can trigger anxiety reactions, because in addition to the disease (at diagnosis, staging, or possible remission) there are concerns about radiation, the duration of the exam, being alone in the image acquisition room, the size of the equipment (particularly in claustrophobic patients), possible positioning discomfort, the injection, and comprehension of the procedures (3).

Anxiety is an emotion characterized by apprehension and somatic symptoms of tension, such as muscle tension and increased heart and respiratory rate (4). It is a complex reaction that results from various situations perceived by patients as a risk. The perception of risk alone is highly dependent on different constructions of danger and vulnerability (5). Anxiety is a state commonly experienced by patients in several fields of medical care but is more prevalent in oncologic contexts $(6,7)$.

The contribution of medical imaging to the diagnosis can be compromised in cases of highly anxious patients since possible movement and muscular tension can reduce image quality by producing motion artifacts and influencing biodistribution, particularly in ${ }^{18} \mathrm{~F}$-FDG PET/CT (8). Recent research has pointed out that providing adequate information and establishing a relationship of trust with health professionals, considering the mental noise often experienced by patients with high levels of anxiety, are key factors in overall patient experience and satisfaction (9).

Regarding PET/CT, Vogel et al. (10) found that 59\% of patients experienced high levels of anxiety before the scan, along with abnormal ${ }^{18}$ F-FDG uptake in tissues. Similarly, Pifarre et al. (11) found that almost two thirds of the patients 
who underwent PET/CT were anxious and that there were higher levels of anxiety in patients who underwent the scan at the initial stage of the disease. Abreu et al. (12) and Grilo et al. (13) observed substantial anxiety before and after the ${ }^{18} \mathrm{~F}-\mathrm{FDG}$ PET/CT scan in oncologic patients. However, in the study of Abreu et al. (12), patients felt more anxious before the scan, whereas in the study of Grilo et al. (13), the anxiety increased after the patients left the uptake room.

Considering BS, Leckie (14) found that patients who received standard information experienced a high degree of anxiety before the scan.

Although these studies have demonstrated that cancer patients experience anxiety during ${ }^{18} \mathrm{~F}-\mathrm{FDG}$ PET/CT (1113) and BS (14), it is not yet clear which factors or procedures might influence anxiety levels or what might be the potential predictors of exam-related anxiety.

Our aim was to assess anxiety levels in cancer patients before and after undergoing BS and ${ }^{18} \mathrm{~F}-\mathrm{FDG}$ PET/CT and to identify the main determinants of anxiety state.

\section{MATERIALS AND METHODS}

\section{Participants}

This cross-sectional prospective study was performed via the collection of questionnaires from cancer patients in a NM department in Lisbon between June and September 2018 who were to undergo ${ }^{99 \mathrm{~m}} \mathrm{Tc}$-hydroxymethylene diphosphonate BS $\left({ }^{99 \mathrm{~m}} \mathrm{Tc}-\mathrm{HDP} \mathrm{BS}\right)$ or ${ }^{18} \mathrm{~F}-\mathrm{FDG}$ PET/CT. The nonprobabilistic sample included individuals over the age of $18 \mathrm{y}$ with an oncologic disease and a cognitive ability to answer questions and participate freely in the study.

\section{Procedure}

The study was authorized by the Ethics Council of the hospital and by the National Data Protection Commission. At the time the exam was scheduled, all patients received oral and written information about the preparation for and duration of the exam.

The ${ }^{99 \mathrm{~m}} \mathrm{Tc}-\mathrm{HDP}$ BS group was informed of the duration of the exam and that no preparation was required for it. The day before the scan, the NM department telephoned each patient to confirm the appointment and to answer any questions about the exam.

The ${ }^{18}$ F-FDG PET/CT group was informed of the duration of the exam and told to fast for $4-6 \mathrm{~h}$ before the scan and not to exercise the day before the scan. The day before the scan, the NM department telephoned all patients to confirm the appointment, to ensure they had received and understood the preparation procedure, and to ask if they had any concerns.

On the day of the exam, all eligible patients were informed of the purpose of the study and that the protection of their data was guaranteed. Data collection was initiated after the patients signed the informed consent form. While the patients completed the prescan and postscan questionnaires, one of the researchers was always present to answer any questions. After filling out the prescan questionnaire, the patients started to undergo the normal procedures of the NM department.

Before the ${ }^{99 \mathrm{~m}} \mathrm{Tc}-\mathrm{HDP}$ BS exam, the technologist told the patient about its purpose, the expected benefits, how it would be performed, and any limitations. Unless contraindicated, the patient should have been well hydrated and was told to drink at least a liter of water during the $2 \mathrm{~h}$ between injection and imaging and to empty the bladder frequently during that time and immediately before the scan. The patient was allowed leave the NM Department during that time, after being educated about the need to maintain social distance.

For the ${ }^{18}$ F-FDG PET/CT exam (15), the patient was kept resting in a warm room for $30-60 \mathrm{~min}$ before receiving the ${ }^{18} \mathrm{~F}-\mathrm{FDG}$ injection and throughout the subsequent uptake period and exam ( $\sim 60 \mathrm{~min}$, to minimize uptake in brown fat). After receiving the injection and during the uptake phase, the patient was asked remain lying down and silent (to minimize uptake in muscles and brain). The patient was asked to drink about $400 \mathrm{~mL}$ of water during the uptake phase and to void the bladder (to ensure a sufficiently low concentration of ${ }^{18} \mathrm{~F}$-FDG in the urine [fewer artifacts] and for radiation safety reasons). The patient also was asked to empty the bladder immediately before the beginning of the scan.

Once the images had been collected and their quality evaluated, the patient was informed of the date on which the report would be delivered and then completed the postscan questionnaire.

\section{Measurement Instruments}

To assess the degree of anxiety, we used the Portuguese version (16) of the Spielberger State Anxiety Inventory (STAI-S) (17). STAI-S evaluates how the patient feels in a particular situation or at a specific moment (e.g., I feel calm; I am angry). Participants are asked to rate themselves on each item based on a 4-point Likert scale, ranging from "not at all" to "very much so." In the end, the scores obtained in each test range from 20 to 80; higher values indicate increased anxiety levels.

The patients completed 2 questionnaires adapted from a previously used instrument for a study on cancer patients undergoing ${ }^{18} \mathrm{~F}-\mathrm{FDG}$ PET/CT $(12,13)$ at 2 different phases: before any contact with the technologist before the scan (prescan) and immediately after image acquisition (postscan). The prescan questionnaire included demographic information (age, sex, and academic degree), exam information (e.g., identification of the procedure name and 1 of 3 possible reasons why it was prescribed: "initial staging of cancer," "treatment results," or "assess cancer recurrence"), the patient's perspective on information provided the day before the scan (e.g., evaluation of its suitability and usefulness on a 7-point Likert scale in which higher values represented a more positive judgment), and a 9-item selfreport questionnaire on patient concerns (e.g., "radiation involved," "not knowing the purpose of the exam," "immobilization or positioning during exam," "exam result," "duration of procedure," "discomfort/pain during the procedure," "lack of knowledge about the procedure," "body exposure during procedure," and "injection of the radiopharmaceutical"). Patients answered each concern on a 7point Likert scale ranging from "not concerned" (1) to "very concerned" (7). The questions about concerns were based on a Portuguese instrument used for cancer patients undergoing radiation treatment (18).

The postscan questionnaire collected the patients' perspective on, and satisfaction with, the information provided by the professionals before the procedure (e.g., evaluation of how comprehensible and useful the information was and whether the professionals allayed the patient's doubts about the scan). The postscan questionnaire also evaluated patient satisfaction with the care provided by the NM department. Patients answered each question on a 7-point Likert scale in which higher values represented a more positive judgment.

\section{Statistical Analysis}

The data were analyzed using the statistical software SPSS, version 22.0, for Microsoft Windows. The Shapiro-Wilk test was 
applied, and results were considered significant at a 5\% level. To compare the subjective perception of anxiety before and after the scan, we used the $t$ test for 2 paired samples. To study the relationship between 2 variables, we used the Pearson correlation coefficient (when the normality assumption was verified) or the Spearman correlation coefficient (when the normality assumption was not verified). To test whether the distribution of a qualitative variable was identical between the 2 groups, we used the $\chi^{2}$ test (when the assumptions of applicability were verified) or the $\chi^{2}$ test by Monte Carlo simulation (when the assumption was not verified). To compare the 2 independent groups, we used the $t$ test (when the normality assumption was verified) or the Mann-Whitney test (when the normality of the sample was not verified). To identify predictors for high levels of anxiety, we used multiple regression analysis with the stepwise method; thus, the prescan STAI-S was considered to be a dependent variable, and the questions raising the highest concerns (e.g., the radiation, exam result, position and duration of the exam, radiopharmaceutical injection, and comprehensibility) were considered to be independent variables. The Gauss-Markov conditions and the lack of multicollinearity were verified for the model.

\section{RESULTS}

\section{Demographics and Clinical Characteristics}

Of the 121 completed questionnaires, 27 were excluded because they lacked a response to at least $60 \%$ of the questions. The sample therefore consisted of 94 patients, 42 of whom underwent ${ }^{99 m}$ Tc-HDP BS and $52{ }^{18} \mathrm{~F}-F D G$ PET/ $\mathrm{CT}$. The mean age of the patients was $62.33 \pm 11.9 \mathrm{y}$ for the ${ }^{99 m}$ Tc-HDP BS group and $59.2 \pm 14.4 \mathrm{y}$ for the ${ }^{18} \mathrm{~F}-\mathrm{FDG}$ PET/CT group. Of all patients, $90.4 \%$ knew why the NM scan had been prescribed. The primary reason for the scans was initial staging of cancer $\left(78.6 \%\right.$ of the ${ }^{99 \mathrm{~m}} \mathrm{Tc}-\mathrm{HDP}$ BS group and $59.6 \%$ of the ${ }^{18} \mathrm{~F}-\mathrm{FDG}$ PET/CT group). Patients who had previously undergone the exam classified their experience as neither very easy nor very difficult (Table 1). Regarding the above characteristics, the 2 groups did not differ significantly $(P>0.05$; Table 1$)$.

\section{Patient Anxiety and Scan-Related Concerns}

When the mean STAI-S scores before and after scanning were compared between the 2 groups, statistically significantly higher scores were found for the ${ }^{99 m}$ Tc-HDP BS group than the ${ }^{18}$ F-FDG PET/CT group before scanning $\left(\mathrm{t}_{47.973}=\right.$ 3.786, $P<0.001$ ) (Table 2). After scanning, the scores were higher in the ${ }^{18} \mathrm{~F}-\mathrm{FDG}$ PET/CT group but not to a statistically significant extent $\left(\mathrm{t}_{70}=-0.768, P=0.445\right)$.

Both groups showed a significant reduction in STAI-S scores between the prescan and postscan questionnaires $\left(\mathrm{t}_{11}=\right.$ $2.450, P=0.032$, for the ${ }^{99 \mathrm{~m} T c-H D P ~ B S}$ group and $\mathrm{t}_{33}=5.252$, $P<0.001$, for the ${ }^{18} \mathrm{~F}-\mathrm{FDG}$ PET/CT group).

Regarding the degree of anxiety, significant moderate to strong positive correlations between the prescan and postscan STAI-S scores $(r=0.670, P<0.001)$ were found for the ${ }^{18} \mathrm{~F}-$ FDG PET/CT group but not for the ${ }^{99 \mathrm{~m}}$ Tc-HDP BS group.

No statistically significant differences in prescan STAI-S scores were found between the sexes for either group or among the different age or educational levels for either group $(P>0.05)$.
No statistically significant differences in prescan STAI-S scores were found between patients undergoing the exam for the first time and patients who had undergone it before (U $=184, P=0.370$, for ${ }^{99 m}$ Tc-HDP BS group and $\mathrm{U}=$ $485, P=0.990$, for ${ }^{18} \mathrm{~F}-\mathrm{FDG}$ PET/CT group).

When analyzing correlations between the patients' evaluation of their previous experience and their prescan and postscan STAI-S scores, we found no correlation for the ${ }^{99 m}$ Tc-HDP BS group. However, for the ${ }^{18} \mathrm{~F}-\mathrm{FDG}$ PET/ CT group a significant moderate to strong positive correlation was found between their previous experience and their prescan STAI-S scores $\left(\mathrm{r}_{\mathrm{S}}=0.634 ; P<0.001\right)$ (Table 3$)$.

For the ${ }^{99 \mathrm{~m}} \mathrm{Tc}-\mathrm{HDP}$ BS group, the greatest concern was the duration of the exam (mean $\pm \mathrm{SD}, 5.3 \pm 2.1$ on the Likert scale), whereas for the ${ }^{18} \mathrm{~F}-\mathrm{FDG}$ PET/CT group the main concern was the result of the exam $(5.4 \pm 1.8)$ (Table 3).

For the ${ }^{18}$ F-FDG PET/CT group, several significant moderate positive correlations with the prescan STAI-S scores were found: the radiation $\left(\mathrm{r}_{\mathrm{S}}=0.352 ; P=0.010\right)$, the result $\left(\mathrm{r}_{\mathrm{S}}=0.306 ; P=0.026\right)$, the duration of the procedure $\left(\mathrm{r}_{\mathrm{S}}=0.399 ; P=0.004\right)$, the body exposure $\left(\mathrm{r}_{\mathrm{S}}=\right.$ $0.328 ; P=0.018)$, and the radiopharmaceutical injection $\left(\mathrm{r}_{\mathrm{S}}=0.341 ; P=0.013\right)$ (Table 3$)$.

\section{Patient Satisfaction with NM Department}

With regard to the patients' overall satisfaction with the NM department, $85.7 \%$ of the total sample were highly satisfied.

Most people in the ${ }^{99 \mathrm{~m}} \mathrm{Tc}-\mathrm{HDP}$ BS $(n=41,97.6 \%)$ and ${ }^{18}$ F-FDG PET/CT $(n=44,84.6 \%)$ groups felt that the information they received the day before and the day of (before) the exam was completely comprehensible (scores on day before exam, $6.00 \pm 1.26$ and $5.69 \pm 1.26$, respectively; scores on day of exam, $6.20 \pm 1.08$ and $6.14 \pm 1.03$, respectively) and useful (scores on day of exam, $5.65 \pm$ 1.43 and $5.82 \pm 1.50$, respectively; scores on day of exam, $6.13 \pm 1.36$ and $6.10 \pm 1.24$, respectively) (Table 4).

When asked if there was any topic they would like to see explained in more detail before the procedure, both groups would have liked more information on the radiation involved (13.5\% for ${ }^{99 m}$ Tc-HDP BS and $7.1 \%$ for ${ }^{18} \mathrm{~F}-$ FDG PET/CT). The ${ }^{99 m}$ Tc-HDP BS group would also have liked more information on duration $(7.1 \%)$, and the ${ }^{18} \mathrm{~F}$ FDG PET/CT group would have liked more information on preparation $(7.7 \%)$.

In the ${ }^{99 \mathrm{~m}} \mathrm{Tc}-\mathrm{HDP}$ BS group, significant moderate positive correlations were found between overall satisfaction and the suitability $\left(\mathrm{r}_{\mathrm{S}}=0.457 ; P=0.003\right)$ and utility $\left(\mathrm{r}_{\mathrm{S}}\right.$ $=0.483 ; P=0.002$ ) of the information provided the day before the exam; the usefulness $\left(\mathrm{r}_{\mathrm{S}}=0.696 ; P<0.001\right)$ and suitability $\left(\mathrm{r}_{\mathrm{S}}=0.655 ; P<0.001\right)$ of the information provided on the day of (before) the exam; and the dignity and respect with which the patient was treated during the exam $\left(\mathrm{r}_{\mathrm{S}}=0.520 ; P=0.001\right)$ (Table 5). Regarding the information provided, there was a significant positive 


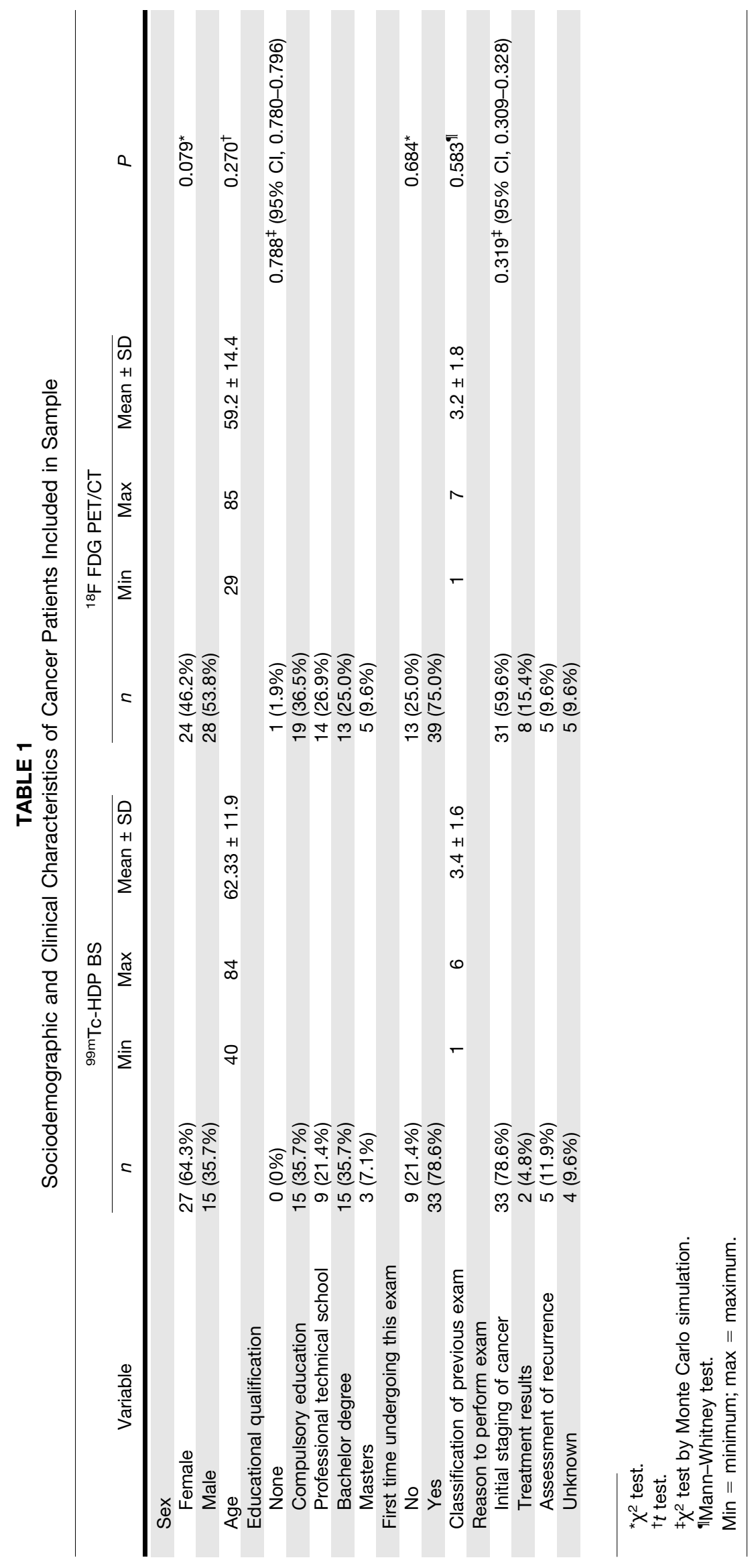

Cancer Patient Experience - Grilo et al. 
TABLE 2

STAI-S Scores Before and After Scanning in Both Groups

\begin{tabular}{|c|c|c|c|c|c|c|c|}
\hline \multirow[b]{2}{*}{ SCAI-S } & \multirow[b]{2}{*}{ Group } & \multicolumn{3}{|c|}{ Group statistics } & \multicolumn{3}{|c|}{ Test statistics } \\
\hline & & Mean & SD & SE mean & $t$ & Df & $P$ \\
\hline \multirow[t]{2}{*}{ Before scanning } & 99mTc-HDP BS & 51.75 & 3.77 & 1.09 & 3.786 & 47.973 & 0.000 \\
\hline & ${ }^{18} \mathrm{~F}-\mathrm{FDG} \mathrm{PET} / \mathrm{CT}$ & 44.67 & 10.00 & 1.52 & & & \\
\hline \multirow[t]{2}{*}{ After scanning } & 99mTc-HDP BS & 36.70 & 12.12 & 2.11 & -0.768 & 70 & 0.445 \\
\hline & ${ }^{18} \mathrm{~F}-\mathrm{FDG}$ PET/CT & 38.82 & 11.33 & 1.81 & & & \\
\hline
\end{tabular}

correlation between comprehensibility and STAI-S scores $\left(\mathrm{r}_{\mathrm{S}}=0.709 ; P=0.049\right)$.

In the ${ }^{18} \mathrm{~F}-\mathrm{FDG}$ PET/CT group, significant moderate positive correlations were found between overall satisfaction and the usefulness $\left(\mathrm{r}_{\mathrm{S}}=0.349 ; P=0.015\right)$ and suitability $\left(\mathrm{r}_{\mathrm{S}}=0.369 ; P=0.010\right)$ of the information provided on the day of (before) the exam and the dignity and respect with which the patient was treated during the exam $\left(\mathrm{r}_{\mathrm{S}}=0.650\right.$; $P<0.001$ ) (Table 5). Regarding the information provided, there was a significant negative correlation between comprehensibility and STAI-S scores $\left(\mathrm{r}_{\mathrm{S}}=-0.386 ; P=0.015\right)$ (Table 4).

\section{Predictors of Anxiety Before Scans}

In the ${ }^{99 m}$ Tc-HDP BS group, only body exposure during the exam was identified as a regressor. For each additional level of concern relating to body exposure, the increase in anxiety averaged 1.288 (Table 6). This model explains $34.1 \%$ of the variation in anxiety levels.

In the ${ }^{18} \mathrm{~F}-\mathrm{FDG} \mathrm{PET} / \mathrm{CT}$ group, the radiation involved and the duration of the exam were identified as regressors. For each additional level of concern involving radiation and exam duration, the increase in anxiety averaged 1.824 and
1.242, respectively (Table 6). This model explains $29.7 \%$ of the variation in prescan anxiety levels.

\section{DISCUSSION}

We evaluated the overall experience and level of anxiety in cancer patients undergoing 2 imaging exams: ${ }^{99 m}$ Tc-HDP $\mathrm{BS}$ and ${ }^{18} \mathrm{~F}$-FDG PET/CT. When the 2 groups were considered separately, no differences in anxiety were found between the sexes or among the various age or educational levels, as agrees with previous studies on cancer patients undergoing imaging or radiation treatment $(11-13,18)$.

Before the exam, we found significant differences in anxiety between the ${ }^{99 \mathrm{~m}}$ Tc-HDP BS and ${ }^{18} \mathrm{~F}-\mathrm{FDG}$ PET/ CT groups (mean state anxiety value, 51.75 and 44.76 , respectively). Similar studies that assessed anxiety through STAI-S encountered lower values. In Leckie's study (14), BS patients who received standard information had a mean anxiety value of 46.0. Grilo et al. (12) found a mean anxiety value of 31.1 in cancer patients who underwent ${ }^{18} \mathrm{~F}-\mathrm{FDG}$ PET/CT. Analogous studies that evaluated cancer patients' anxiety before radiation treatment $(18,19)$ and chemotherapy (20) presented more moderate values than those observed in our study.

TABLE 3

Descriptive Measurements of Patients' Concerns About NM Exam and Correlations with STAI-S Before Scanning

\begin{tabular}{|c|c|c|c|c|c|c|c|c|}
\hline \multirow[b]{2}{*}{ Concern } & \multicolumn{4}{|c|}{ 99mTc-HDP BS } & \multicolumn{4}{|c|}{${ }^{18} \mathrm{~F}$ FDG PET/CT } \\
\hline & Mean \pm SD & Min & Max & Correlation & Mean \pm SD & Min & Max & Correlation \\
\hline Radiation involved & $3.33 \pm 1.76$ & 1 & 7 & 0.182 & $3.027 \pm 2.05$ & 1 & 7 & $0.352^{\star}$ \\
\hline Not knowing purpose of exam & $2.85 \pm 1.84$ & 1 & 7 & -0.073 & $2.257 \pm 1.69$ & 1 & 7 & 0.035 \\
\hline Immobilization or positioning & $2.53 \pm 1.95$ & 1 & 7 & 0.084 & $2.88 \pm 2.13$ & 1 & 7 & 0.263 \\
\hline Exam result (diagnostic) & $2.85 \pm 1.96$ & 1 & 7 & 0.065 & $5.40 \pm 1.80$ & 1 & 7 & $0.306^{*}$ \\
\hline Duration of scan & $5.34 \pm 2.08$ & 1 & 7 & -0.043 & $3.64 \pm 2.06$ & 1 & 7 & $0.399^{\dagger}$ \\
\hline Discomfort or pain during scan & $3.49 \pm 1.90$ & 1 & 7 & -0.026 & $2.92 \pm 1.95$ & 1 & 7 & 0.217 \\
\hline Lack of knowledge about scan & $3.24 \pm 2.17$ & 1 & 7 & 0.070 & $2.96 \pm 2.06$ & 1 & 7 & 0.122 \\
\hline Body exposure during scan & $3.17 \pm 1.99$ & 1 & 7 & $0.338^{\star}$ & $3.04 \pm 2.10$ & 1 & 7 & $0.328^{*}$ \\
\hline Injection of radiopharmaceutical & $2.55 \pm 1.76$ & 1 & 7 & 0.016 & $3.58 \pm 2.09$ & 1 & 7 & $0.341^{*}$ \\
\hline
\end{tabular}

*Statistically significant at $<0.05$ level.

tStatistically significant at $<0.01$ level.

Min = minimum; $\max =$ maximum. 
TABLE 4

Patients' Appraisal of Information Provided Before Scanning, and Correlations with STAI-S Before Scanning

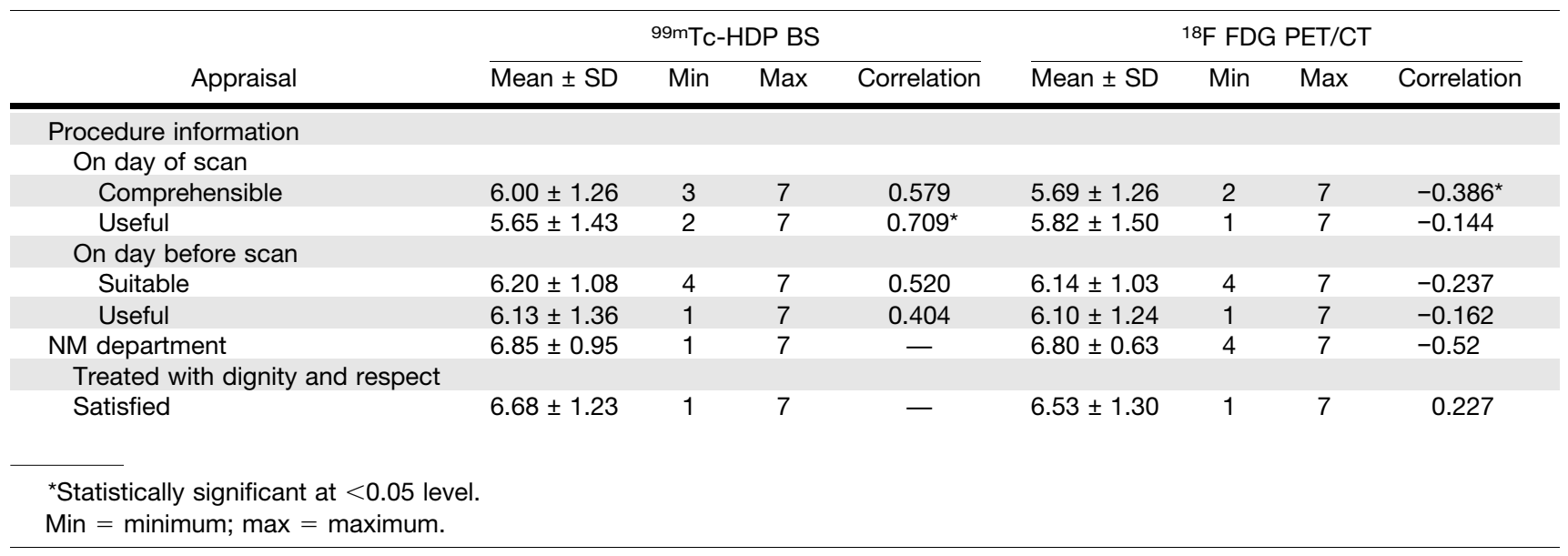

With respect to exam-related concerns, exam duration was the main trigger of anxiety for patients in the ${ }^{99 \mathrm{~m}} \mathrm{Tc}-$ HDP BS group. In the ${ }^{18} \mathrm{~F}-\mathrm{FDG} \mathrm{PET} / \mathrm{CT}$ group, the results of the exam were the major source of concern. In both cases, the variables were independent of the patients' familiarity with the procedures. Since the sample was composed exclusively of oncologic patients, it is noteworthy that anxiety levels during subsequent exams were not always inferior. The fact that both scans are often performed for staging, assessing response to therapy, and evaluating possible recurrence implies that there may be a disease setback at any time (21).

Only in the ${ }^{18} \mathrm{~F}$-FDG PET/CT group were higher scores for previous exams (a more negative experience) associated with higher STAI-S scores before the exam (greater anxiety). These results are consistent with other studies, verifying that past experiences, whether satisfactory or not, deeply affect a patient's conception of the procedure $(9,22)$.

TABLE 5

Correlation of Patients' Overall Satisfaction with Information Provided on Day of Scanning and Day Before Scanning

\begin{tabular}{|c|c|c|c|c|c|}
\hline \multirow[b]{2}{*}{ Group } & \multicolumn{2}{|c|}{$\begin{array}{c}\text { Procedure information } \\
\text { Day before } \\
\text { scan }\end{array}$} & \multicolumn{2}{|c|}{ NM department } & \multirow[b]{2}{*}{ Satisfied } \\
\hline & $\begin{array}{c}\text { Day of } \\
\text { scan (utility) }\end{array}$ & Suitable & Useful & $\begin{array}{l}\text { Treated with dignity } \\
\text { and respect }\end{array}$ & \\
\hline \multicolumn{6}{|l|}{ 99mTc-HDP BS } \\
\hline \multicolumn{6}{|l|}{ Procedure information } \\
\hline \multicolumn{6}{|l|}{ Day of scan } \\
\hline Comprehensible & $0.831^{*}$ & $0.504^{*}$ & $0.497^{*}$ & 0.164 & $00.655^{\star}$ \\
\hline Useful & & $0.633^{\star}$ & $0.581^{*}$ & 0.093 & $00.696^{\star}$ \\
\hline \multicolumn{6}{|l|}{ Day before scan } \\
\hline Suitable & & & $0.944^{*}$ & 0.197 & $0.457^{\star}$ \\
\hline Useful & & & & 0.189 & $0.483^{*}$ \\
\hline NM department (treated with dignity and respect) & & & & & $0.520^{\star}$ \\
\hline \multicolumn{6}{|l|}{ PET/CT } \\
\hline \multicolumn{6}{|l|}{ Procedure information } \\
\hline \multicolumn{6}{|l|}{ Day of scan } \\
\hline Comprehensible & $0.847^{\star}$ & 0.296 & 0.155 & $0.430^{*}$ & $00.369^{*}$ \\
\hline Useful & & $0.444^{\star}$ & 0.270 & 0.122 & $00.349^{\dagger}$ \\
\hline Day before scan & & & $0.547^{*}$ & -0.136 & -0.224 \\
\hline Suitable & & & & -0.139 & -0.218 \\
\hline \multicolumn{6}{|l|}{ Useful } \\
\hline NM department (treated with dignity and respect) & & & & & $0.650^{*}$ \\
\hline $\begin{array}{l}\text { *Statistically significant at }<0.01 \text { level (2-tailed). } \\
\text { †Statistically significant at }<0.05 \text { level ( } 2 \text {-tailed). } \\
\text { Data are Spearman correlation coefficient. }\end{array}$ & & & & & \\
\hline
\end{tabular}


TABLE 6

Model of Multiple Regression Analysis to Identify Patients' Anxiety Regressors Before Scanning

\begin{tabular}{|c|c|c|c|c|c|c|}
\hline Group & Model & Parameter & $\beta$ & $R^{2}$ change & Adjusted $R^{2}$ & F change \\
\hline \multirow[t]{2}{*}{ 99mTc-HDP BS } & 1 & Constant & $47.183^{*}$ & 0.407 & 0.341 & $6.186^{\star}$ \\
\hline & & Exposure of body & $1.282^{\dagger}$ & & & \\
\hline \multirow[t]{5}{*}{${ }^{18} \mathrm{~F}-\mathrm{FDG} \mathrm{PET} / \mathrm{CT}$} & 1 & Constant & 37.519 & 0.258 & 0.238 & $13.212^{*}$ \\
\hline & & Radiation & $2.219^{*}$ & & & \\
\hline & 2 & Constant & 34.292 & 0.075 & 0.297 & $4.174^{*}$ \\
\hline & & Radiation & $1.824^{*}$ & & & \\
\hline & & Duration & $1.242^{*}$ & & & \\
\hline
\end{tabular}

*Statistically significant at $<0.05$ level.

tStatistically significant at $<0.01$ level.

Unexpectedly, body exposure during the exam was the only anxiety predictor identified among cancer patients who underwent ${ }^{99 m}$ Tc-HDP BS (accounting for $34.1 \%$ of the variation in anxiety levels). On the day before the exam, patients were contacted to confirm their appointment and to clarify any doubts about the procedure that they might be experiencing at that moment. However, the details of the procedure were not explained thoroughly if the patient did not ask specific questions. Some patients may have anticipated that the exam would include a phase in which their body would be exposed (undressed). A study by Bahrami et al. (23) identified body image disturbance in most of the cancer patients, irrespective of the type and duration of illness. Additionally, other studies involving cancer patients treated surgically revealed dissatisfaction with appearance (24) and embarrassment about their body changes in relation to the disease (25). These data allowed us to hypothesize that in the BS group, patients had body image concerns; nonetheless, further discussion is needed. We need to understand exactly how body-exposure concerns affect patients emotionally and why this predictor of anxiety appeared exclusively in the ${ }^{99 \mathrm{~m}} \mathrm{Tc}-\mathrm{HDP}$ BS group.

In the ${ }^{18}$ F-FDG PET/CT group, the radiation and duration of the exam were identified as predictors (accounting for $29.7 \%$ of the variation in anxiety levels). The word radiation often evokes fear in patients, family members, and health professionals. Radiation is perceived as a risk. This perception has several sources, including public information on actual biologic risks from exposure to radiation (26). A recent study evaluating patient knowledge and communication preferences concluded that there is a substantial difference between patients' expectations and current practices for providing information about medical imaging using ionizing radiation (22). One of the main objectives of risk communication in health care is to ensure that patients or caregivers are provided with needed, understandable information (27). In our ${ }^{18} \mathrm{~F}-\mathrm{FDG}$ PET/CT group, patients who assessed the information as being less comprehensive experienced greater state anxiety. Both groups mentioned that it would be beneficial to further address issues such as the radiation burden involved. It is imperative to obtain a better understanding of the population's knowledge about radiation and to demystify it, as it remains a source of great concern and ultimately would be a starting point for creating communication guidelines for cancer patients in NM. Similarly, with previous studies $(12,13)$ the mean anxiety levels for both groups decreased after the scan had been performed. Interestingly, after the scan, the ${ }^{18} \mathrm{~F}-\mathrm{FDG}$ PET/ CT group was slightly more anxious than the $99 \mathrm{~m}$ Tc-HDP BS group. In addition, higher anxiety scores in the ${ }^{18} \mathrm{~F}-\mathrm{FDG}$ PET/CT group before the scan were associated with higher postscan STAI-S scores. Considering that the result of the exam was the main concern for the ${ }^{18}$ F-FDG PET/CT group, it seems that the patients' uncertainty about the results (28) and the awareness that the results may determine future treatments or the course of the disease $(12,13)$ hindered a further reduction in anxiety for this group (12).

The questionnaires also allowed us to pinpoint the fact that many patients in both groups considered the information provided before the exam to be completely comprehensible and therefore were very satisfied with the department. Such results are supported by previous studies correlating the information provided with the overall satisfaction with the department $(12,14,29)$. This satisfaction is associated not only with the fact that a more knowledgeable patient tends to be more cooperative, thus smoothing the process, but also with the opportunity granted to the technologist of establishing a relationship of trust (30). Levels of patient anxiety can be diminished when the involved professionals show signs of support and care and when they treat the patient with dignity (14).

Our study showed that although the lines of communication were good, it is always possible to improve and facilitate troublesome procedures such as the injection and positioning (30) and to provide the information that patients truly need (31). Although more studies are needed to better understand the variance that remains unexplained in models that predict exam-related anxiety, the present research offers significant contributions for NM departments. The data encourage health-care professionals to look for a more effective means of preparing patients and to adjust the timing and level of detail of the information provided for each exam. With respect to timing, the high levels of anxiety on arrival at the 
NM department (as shown on the prescan questionnaire) support the suggestion of some authors $(32,33)$ that the NM department should find a better way to provide patients with information before the day of the exam. Patients need enough direct information to understand the procedures and decrease any unpredictability about the scan $(14,34)$.

For patients who are to undergo ${ }^{99 \mathrm{~m}} \mathrm{Tc}-\mathrm{HDP} \mathrm{BS}$, it seems necessary to provide more detail on duration and body exposure before the day of the scan. To minimize concerns about duration, staff should emphasize that relatives can stay with the patient during the uptake period and that the patient can even leave the NM department during this time. Regarding body exposure, staff can provide a link to a video that shows patients what will happen during the image acquisition (i.e., shows that there will be no need to be undressed). Educational videos deliver information in a consistent manner (35) and have yielded positive outcomes for cancer patients (35-37).

To minimize the 2 identified predictors of exam-related anxiety in patients who are to undergo ${ }^{18} \mathrm{~F}-\mathrm{FDG} \mathrm{PET} / \mathrm{CT}$, it may be helpful to provide them with an information leaflet or a link to a slide presentation. These practices have a minimal cost, do not disrupt the department's workflow, and are useful in improving understanding of the scan procedure $(14,19,33)$. The information should cover details about the radiopharmaceutical, discuss misconceptions about radiation use, and specify what the patient will do while in the NM department. In addition, concerns about the exam results-found in the ${ }^{18} \mathrm{~F}-\mathrm{FDG}$ PET/CT group-must not be disregarded. Promoting patient-centered oncology care (24), especially during anamnesis (e.g., considering patients' previous exam experiences), and offering a safe, calm, enlightened, and supportive environment $(11,19)$ will allow the patient to feel well cared for and understood $(24,38)$. Suggesting simple cognitive and relaxation strategies will also reduce anxiety levels (33).

We encountered several limitations during the study. First, our sample size was small, as it included patients in only a single NM department. A larger sample of oncologic patients followed up by different health services would be more impactful. Second, self-reporting questionnaires are the most common methodology for studying topics such as anxiety and patient experience but are not without issues. The patients' understanding of the questions is one of the main apprehensions. When our patients were completing the questionnaires, they were asked to check with one of the researchers in the room if they were uncertain about any of the questions. However, this instruction did not prevent interpretations that differed from those of the authors. Furthermore, the questionnaires asked whether patients would like more information about the exam but did not ask what specific information they desired (e.g., on radiation or duration). Further research that includes these data is required. Third, because a large number of questionnaires were incomplete and had to be eliminated, we hypothesize that some patients found them too long or arduous (especially the postscan questionnaire, after the patient had spent hours in the NM department). This observation highlights the importance of developing shorter but psychometrically robust questionnaires that can provide relevant information without excessively burdening the patients.

\section{CONCLUSION}

Our study revealed major sources of patient anxiety, especially before undergoing scanning. The group that underwent ${ }^{99 \mathrm{~m} T c-H D P}$ BS proved to be more anxious than the ${ }^{18} \mathrm{~F}-\mathrm{FDG}$ PET/CT group. The main concern presented by the ${ }^{99 \mathrm{~m}} \mathrm{Tc}-\mathrm{HDP}$ BS group was the duration of the exam, whereas body exposure during the exam was the only predictor of exam-related anxiety. For the ${ }^{18} \mathrm{~F}$-FDG PET/CT group, the main concern was the exam result, whereas the radiation involved in the exam and the duration of the exam were identified as significant predictors of exam-related anxiety. Awareness of these specific anxiety concerns and predictors for each of these 2 exams enables NM department professionals to develop patient information of greater depth and to better communicate this information.

\section{DISCLOSURE}

No potential conflict of interest relevant to this article was reported.

\section{ACKNOWLEDGMENTS}

We thank Stephanie Lewis for language-editing our paper. Our thanks also go to all the patients who participated in this study and the Nuclear Medicine Technologists Ana Mota and Lucinda Dias who cooperated on this study.

\section{REFERENCES}

1. Almuhaideb A, Papathanasiou N, Bomanji J. ${ }^{18}$ F-FDG PET/CT imaging in oncology. Ann Saudi Med. 2011;31:3-13.

2. Van den Wyngaert T, Strobel K, Kampen WU, et al. The EANM practice guidelines for bone scintigraphy. Eur J Nucl Med Mol Imaging. 2016;43:1723-1738.

3. Dauer LT, Thornton RH, Hay JL, Balter R, Williamson MJ, St Germain J. Fears, feelings, and facts: interactively communicating benefits and risks of medical radiation with patients. AJR. 2011;196:756-761.

4. APA Dictionary of Psychology: anxiety. American Psychological Association website. https://dictionary.apa.org/anxiety. Accessed July 27, 2020.

5. Sandman PM. Responding to community outrage: strategies for effective risk communication. The Peter M. Sandman Risk Communication website. http:// psandman.com/media/RespondingtoCommunityOutrage.pdf. Published 1993. Accessed July 27, 2020.

6. Perry L, Burgess M. Communication in Cancer Care. Oxford, U.K.: Blackwell Publishing; 2002:27-45.

7. Mathers SA, McKenzie GA, Robertson EM. A necessary evil: the experiences of men with prostate cancer undergoing imaging procedures. Radiography. 2011;17:284-291.

8. Ahmad Sarji S. Physiological uptake in FDG PET simulating disease. Biomed Imaging Interv J. 2006;2:e59.

9. Acuff SN, Bradley YC, Barlow P, Osborne DR. Reduction of patient anxiety in PET/CT imaging by improving communication between patient and technologist. J Nucl Med Technol. 2014;42:211-217.

10. Vogel WV, Valdes RA, Tijs TJ, Gillies MF, van Elswijk G, Vogt J. Intervention to 382 lower anxiety of ${ }^{18}$ F-FDG PET/CT patients by use of audiovisual imagery during the uptake phase before imaging. J Nucl Med Technol. 2012;40:92-98.

11. Pifarré P, Simó M, Gispert JD, Pallarés MD, Plaza P, Martínez-Miralles E. Diagnostic imaging tests: do they generate anxiety? [in Spanish]. Rev Esp Med Nucl Imagen Mol. 2011;30:346-350. 
12. Abreu C, Grilo A, Lucena F, Carolino E. Oncological patient anxiety in imaging studies: the PET/CT example. J Cancer Educ. 2017;32:820-826.

13. Grilo A, Vieira L, Carolino E, et al. Anxiety in cancer patients during ${ }^{18}$ F-FDG PET/CT low dose: a comparison of anxiety levels before and after imaging studies. Nurs Res Pract. 2017;2017:3057495.

14. Leckie J. The effects of informational intervention on state anxiety and satisfaction in patients undergoing bone scan. Nucl Med Commun. 1994;15:921-927.

15. Boellaard R, Delgado-Bolton R, Oyen WJ, et al. FDG PET/CT: EANM procedure guidelines for tumour imaging-version 2.0. Eur J Nucl Med Mol Imaging. 2015;42:328-354.

16. Silva D. O inventário de estado-traço de ansiedade (STAI) [The state-trait anxiety inventory (STAI)]. In: Avaliação Psicológica: Instrumentos Validados Para a População Portuguesa [Psychological Assessment: Validated Instruments for the Portuguese Population]. Coimbra, Portugal: Quarteto Editora; 2003:45-63.

17. Spielberger D, Gorsuch RL, Lushene PR, Vagg PR, Jacobs GA. Manual for the State-Trait Anxiety Inventory (Form Y). Palo Alto, CA: Consulting Psychologists Press; 1983.

18. Grilo AM, Gomes AI, Monsanto F, Albino D, Augusto C, Pragana C. First day of radiotherapy for women with breast cancer: predictors of anxiety. Support Care Cancer. 2020;28:1241-1248.

19. Schnitzler L, Smith SK, Shepherd HL, et al. What information is communicated by radiation therapists to patients during education sessions on the first day of treatment? Eur J Cancer Care (Engl). 2019;28:e12911.

20. Schneider A, Kotronoulas G, Papadopoulou C, et al. Trajectories and predictors of state and trait anxiety in patients receiving chemotherapy for breast and colorectal cancer: results from a longitudinal study. Eur J Oncol Nurs. 2016;24:1-7.

21. Khalil A, Faheem M, Fahim A, et al. Prevalence of depression and anxiety amongst cancer patients in a hospital setting: a cross-sectional study. Psychiatry J. 2016;2016:3964806.

22. Andersson C, Johansson B, Wassberg C, Johansson S, Sundin A, Ahlstrom Hl. Assessment of whether patient's knowledge, satisfaction and experience regarding their ${ }^{18} \mathrm{~F}$-fluoride PET/CT examination affects image quality. $\mathrm{J} \mathrm{Nucl} \mathrm{Med}$ Technol. 2016;44:21-25.

23. Bahrami M, Mohamadirizi M, Mohamadirizi S, Hosseini SA. Evaluation of body image in cancer patients and its association with clinical variables. $J$ Educ Health Promot. 2017;6:81.

24. Ellis MA, Sterba KR, Brennan EA, et al. A systematic review of patient-reported outcome measures assessing body image disturbance in patients with head and neck cancer. Otolaryngol Head Neck Surg. 2019;160:941-954.
25. Fingeret MC, Hutcheson KA, Jensen K, Yuan Y, Urbauer D, Lewin JS. Associations among speech, eating, and body image concerns for surgical patients with head and neck cancer. Head Neck. 2013;35:354-360.

26. Kuroda Y. Current state and problems of radiation risk communication: based on the results of a 2012 whole village survey. PMC website. https://www.ncbi.nlm.nih.gov/ pmc/articles/PMC5375389/. Published February 24, 2017. Accessed July 27, 2020.

27. Peck DJ, Samei E. How to understand and communicate radiation risk. Image Wisely website. https://www.imagewisely.org/Imaging-Modalities/Computed-Tomography/ How-to-Understand-and-Communicate-Radiation-Risk. Updated March 2017. Accessed July 27, 2020.

28. Thorpe S, Salkovskis PM, Dittner A. Claustrophobia in MRI: the role of cognitions. Magn Reson Imaging. 2008;26:1081-1088.

29. Reyes-Pérez M, Rodrigo-Rincón MI, Martínez-Lozano ME, et al. Evaluation of the grade of satisfaction of the patient attendants and the nuclear medicine service [in Spanish]. Rev Esp Med Nucl Imagen Mol. 2012;31:192-201.

30. Kaya E, Ciftci I, Demirel R, Cigerci Y, Gecici O. The effect of giving detailed information about intravenous radiopharmaceutical administration on the anxiety level of patients who request more information. Ann Nucl Med. 2010;24: 67-76.

31. Munn Z, Jordan Z. The effectiveness of nonpharmacologic interventions to reduce anxiety and increase patient satisfaction and comfort during nuclear medicine imaging. J Med Imaging Radiat Sci. 2014;45:47-54.

32. Clarke SE, McKillop JH, Prescott MC, Williams ED. Information for patients and staff concerning nuclear medicine. Nucl Med Commun. 1992;13:271-281.

33. Grey SJ, Price G, Mathews A. Reduction of anxiety during MR imaging: a controlled trial. Magn Reson Imaging. 2000;18:351-355.

34. Munn Z, Jordan Z. The patient experience of high technology medical imaging: a systematic review of the qualitative evidence. JBI Libr Syst Rev. 2011;9:631-678.

35. Williams K, Blencowe J, Ind M, Willis D. Meeting radiation therapy patients informational needs through educational videos augmented by $3 \mathrm{D}$ visualisation software. J Med Radiat Sci. 2017;64:35-40.

36. Stewart-Lord A, Brown M, Noor S, Cook J, Jallow O. The utilisation of virtual images in patient information giving sessions for prostate cancer patients prior to radiotherapy. Radiography. 2016;22:269-273.

37. Sule-Suso J, Finney S, Bisson J, et al. Pilot study on virtual imaging for patient information on radiotherapy planning and delivery. Radiography. 2015;21:273277.

38. Ramlaul A, Vosper A. Patient Centred Care in Medical Imaging and Radiotherapy. London, U.K.: Churchill Livingstone; 2013:307. 